\title{
Lisdexamfetamine dimesylate in the treatment of attention-deficit/ hyperactivity disorder: pharmacokinetics, efficacy and safety in children and adolescents
}

\author{
Dimesilato de lisdexanfetamina no tratamento do transtorno do déficit de atenção e hiperatividade: \\ farmacocinética, eficácia e segurança em crianças e adolescentes
}

\author{
Paulo Mattos ${ }^{1}$ \\ ${ }^{1}$ Universidade Federal do Rio de Janeiro (UFRJ), Brazil.
}

Received: 1/15/2014 - Received: 5/5/2014

DOI: 10.1590/0101-60830000000007

\begin{abstract}
Background: Psychostimulants (methylphenidate and amphetamines) are considered first-line therapy for attention-deficit/hyperactivity disorder (ADHD). Lisdexamfetamine dimesylate (LDX) is a new psychostimulant approved for the treatment of ADHD in Brazil. The pharmacologically active fraction, $d$-amphetamine, is gradually released by hydrolysis of the LDX prodrug. Objectives: To perform a systematic review of the literature of the efficacy and safety of LDX in the treatment of ADHD in children and adolescents. Methods: Medline/PubMed searches for "d-amfetamine", "lisdexamfetamine" and "lisdexamfetamine dimesylate" were conducted including articles available from January 2000 to November 2013. Additional references were identified using references listed in those articles. Further data on LDX were requested from its manufacturer. Results: Thirty-one papers were found related to ADHD treatment in children and adolescents. Discussion: The therapeutic benefits of LDX in children with ADHD are achieved as early as 1.5 hours after its administration and last for up to 13 hours, with efficacy comparable or superior to that of other available psychostimulants. The literature also reports efficacy in long-term treatment, with safety and tolerability profiles comparable to those of other stimulants used for the treatment of ADHD. Most of the adverse events associated with LDX are considered to be mild or moderate in severity, with the most common being loss of appetite and insomnia.
\end{abstract}

Mattos P / Rev Psiq Clín. 2014;41(2):34-9

Keywords: Attention-deficit/hyperactivity disorder, efficacy, lisdexamfetamine dimesylate, pharmacokinetics, safety.

\section{Resumo}

Contexto: Psicoestimulantes (metilfenidato e anfetaminas) são considerados como tratamento farmacológico de primeira linha no tratamento do transtorno do déficit de atenção e hiperatividade (TDAH). O dimesilato de anfetamina é um novo psicoestimulante aprovado para uso no Brasil, cuja fração farmacologicamente ativa, a $d$-anfetamina, é gradualmente liberada por hidrólise da pró-droga. Objetivos: Realizar uma revisão sistemática de literatura sobre eficácia e segurança da LDX no tratamento de TDAH de crianças e adolescentes. Métodos: Busca na base Medline/PubMed com os termos "d-amfetamine", "lisdexamfetamine" e "lisdexamfetamine dimesilate", de janeiro de 2000 até novembro de 2013. Referências adicionais foram retiradas das referências dos artigos obtidos; dados também foram obtidos do fabricante. Resultados: Trinta e um artigos foram encontrados, relacionados ao tratamento de TDAH em crianças e adolescentes. Conclusões: Os benefícios terapêuticos da LDX são obtidos em até 1,5 hora após administração e se estendem até 13 horas, com eficácia comparável ou superior à dos demais psicoestimulantes disponíveis. A literatura também documenta eficácia em longo prazo, com perfis de segurança e tolerabilidade comparáveis aos dos demais estimulantes usados no tratamento do TDAH. A maioria dos eventos adversos associados à LDX é considerada leve ou moderada quanto à gravidade, sendo os eventos mais comuns perda de apetite e insônia.

Mattos P / Rev Psiq Clín. 2014;41(2):34-9

Palavras-chave: Transtorno do déficit de atenção e hiperatividade, eficácia, dimesilato de anfetamina, farmacocinética, segurança.

\section{Introduction}

Attention-deficit/hyperactivity disorder (ADHD) is characterized by inattention, hyperactivity and impulsiveness at levels higher than expected for age. ADHD has been described in various cultures and societies as the most common neurobehavioral disorder in children $^{1}$, and is associated with poor performance in family, social and academic contexts, especially when not diagnosed and treated effectively ${ }^{2-5}$. The most widely documented negative effects of ADHD include poor school performance in children and adolescents. For example, even considering family income and the parents' level of education as significant variables in academic performance (an aspect especially important in countries such as Brazil), ADHD is associated with poorer academic performance ${ }^{6}$.
The prevalence of ADHD worldwide in children under 18 years old is estimated at $5.3 \%$, with greater frequency of recognition in children than in adolescents, and in boys than in girls ${ }^{7}$. In studies in Brazil, the estimates of ADHD prevalence in children and adolescents range from $5.8 \%$ to $19.9 \%$, and vary depending on the diagnostic criteria used and the type of sample analyzed ${ }^{8-11}$. ADHD often persists beyond adolescence into adulthood, although the presentation of symptoms differs between adults, children, and adolescents $^{12}$.

Despite the extensive scientific literature and dozens of associations formed by people with ADHD and family members throughout the world, there are still substantial misconceptions about the nature of ADHD and its treatment. In a survey conducted in Brazil of representative groups of physicians, psychologists, teachers and the general public, each of these groups reported beliefs that were not based on scientific evidence ${ }^{13}$. For example, among physicians, more than $50 \%$ of pediatricians and neurologists expressed the belief that $\mathrm{ADHD}$ was the result of absent parents. In addition, more than 
$50 \%$ of the psychologists expressed the belief that ADHD can be treated with psychotherapy alone.

Treatment strategies for ADHD include counseling, psychoeducation, psychotherapy, and pharmacological treatment. Behavioral parent training, behavior management in the classroom and behavior interventions in various contexts are considered to be effective in managing $\mathrm{ADHD}^{14}$. Pharmacological therapy is an important part of management of ADHD, with psychostimulants considered first line therapy ${ }^{15}$.

Psychostimulants are considered the most effective of all the medications used to treat $\mathrm{ADHD}^{16}$, and are available in immediateand prolonged-release formulations. Potential limitations of the use of immediate-release formulations include the need for frequent doses that potentially reduce adherence, and fluctuations in serum levels which have been associated with adverse events. Although there is some evidence for this, it is not yet clear whether immediate-release psychostimulants produce greater abuse potential than prolonged-release formulations ${ }^{17}$. Among the prolonged action psychostimulants used in treating ADHD, there are various formulations of methylphenidate and amphetamine (with differing means of release and half-lives). A recent Cochrane review demonstrated the efficacy of amphetamines in treating this disorder ${ }^{18}$. Lisdexamfetamine dimesylate (LDX) is the newest drug in this class, having been developed as a prodrug of dextroamphetamine ( $d$-amphetamine) aimed at providing long-acting treatment effects and a reduced risk of abuse ${ }^{19}$. The purpose of this article is to review the pharmacokinetics, efficacy and safety of LDX in treating ADHD in children and adolescents.

\section{Methods}

Medline/PubMed searches for lisdexamfetamine were conducted including articles available form January 2000 to November 2014. Additional references were identified using the reference lists of those articles. Further data on LDX were requested from its manufacturer. The articles included were selected based on the author's decision of their relevance to the topic.

\section{Results}

Forty-one papers were found related to ADHD treatment with lisdexamfetamine in children and adolescents with ADHD. They were sorted by topics, as indicated below.

\section{Pharmacokinetics}

LDX is administered orally as an inactive parent compound that is rapidly and almost completely absorbed in the gastrointestinal tract. LDX is subsequently metabolized by enzyme hydrolysis into 1-lysine (an essential amino acid) and $d$-amphetamine, the active component ${ }^{17,20}$ (Figure 1). The hydrolysis of the inactive component to the active drug is a relatively slow process that occurs mainly in the blood ${ }^{19-21}$. It has been suggested that this relatively slow stage contributes to the long-lasting effect and possibly also to reduced "drug craving", an aspect considered critical in the development of abuse after both oral and intravenous administration ${ }^{19,22}$.

In children 6-12 years of age, the time to maximum blood concentration ( $\mathrm{T}$ ) of $d$-amphetamine after the administration of a single dose of LDX $(30,50$ or $70 \mathrm{mg})$ was 3.4-3.6 hours and the half-life was 8.6-8.9 hours, with no significant differences among the various doses ${ }^{21}$. These parameters are similar to those of the immediate-release formulations of mixed-salt psychostimulants, but shorter than the $\mathrm{T}_{\max }$ of prolonged-release formulations such as Adderall XR (Shire U.S., Inc., East Hanover, NJ, U.S.; $\mathrm{T}_{\max }=$ 7 hours). Systemic exposure to $d$-amphetamine showed that the maximum blood concentration $\left(\mathrm{C}_{\max }\right)$, area under the curve (AUC) from time zero to infinity $\left(\mathrm{AUC}_{0-\infty}\right)$ and $\mathrm{AUC}$ from time zero to the last measurable concentration $\left(\mathrm{AUC}_{0^{-}}\right)$was proportional to the dose, with low interpatient variation. Furthermore, in another study that measured $\mathrm{C}_{\max }, \mathrm{T}_{\max }$ and AUC in children 6-12 years of age with ADHD, the interpatient variability (as measured by the coefficient of variation) for these parameters was lower for $d$-amphetamine following administration of a $70 \mathrm{mg}$ dose of LDX than following the administration of $30 \mathrm{mg}$ of extended-release mixed amphetamine salts $^{23}$. This suggests that the concentrations of the active metabolite are proportional to the dose of LDX, with low variation among individuals ${ }^{21,24}$.

Some controlled-release formulations of psychostimulants are sensitive to alterations in gastric $\mathrm{pH}$ (e.g., due to the concomitant presence of antacids or proton pump inhibitors) or gastrointestinal transit time, potentially leading to pharmacokinetic variability ${ }^{25}$. Significant variations in the plasma levels of $d$-amphetamines were reported when one compared their administration with and without food intake (Adderall XR) ${ }^{26,27}$. It has been demonstrated in vitro that the solubility of LDX is not affected by $\mathrm{pH}$ within a physiologically relevant range $(\mathrm{pH}=1-8)$, and is slightly reduced when the $\mathrm{pH}$ is substantially increased $(\mathrm{pH}=8-13)^{20}$. Given that LDX is a prodrug and not dependent on a controlled-release mechanism, the changes in gastrointestinal transit should not alter its effects ${ }^{20}$. Furthermore, food does not significantly or clinically affect the bioavailability of $\mathrm{LDX}^{28}$. The administration of a single dose of LDX after a high-fat meal compared with a fasting state resulted in a delay of approximately 1 hour in $d$-amphetamine $\mathrm{T}_{\max }$, although the $\mathrm{C}_{\max }$ and AUC were similar ${ }^{28}$.

LDX has demonstrable efficacy 2 hours after administration that is maintained up to 12 hours $^{23}$. Another study reported beneficial effects of LDX lasting from 1.5 to 13 hours post-dose ${ }^{29}$. In a 4-week, double-blind, randomized study in children, the evening rebound associated with LDX proved to be less than with placebo $(2.9 \%$ vs $9.7 \%$, respectively $)^{30}$. Such aspects are potentially relevant for clinical practice due to the need for symptomatic control during various activities throughout the day ${ }^{23}$. In addition, the consistent plasma concentrations of the drug prevented fluctuations and the associated rebound effects. Furthermore, the absence of fluctuations
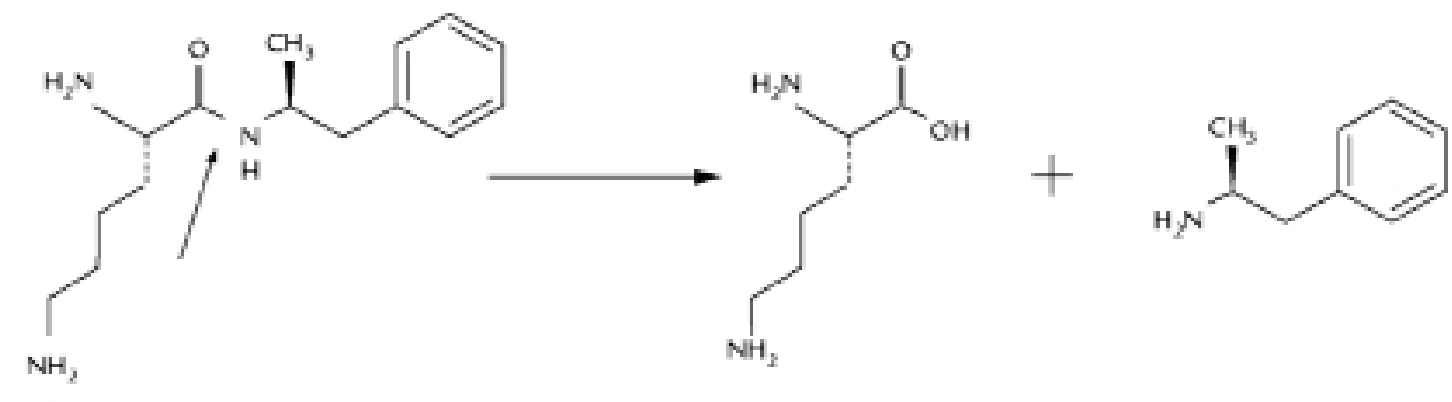

d-amphetamine

Figure 1. Enzymatic activation of the prodrug (lisdexamfetamine dimesylate) for the active compound of d-amphetamine. 
in plasma concentrations (peaks and troughs) throughout the day minimized or eliminated the "sudden-onset" or "peak" effects potentially related to abuse ${ }^{31}$. In a study of potential abuse of LDX comparing intranasal administration with oral administration, similar values were found for $\mathrm{C}_{\max }, \mathrm{T}_{\max }, \mathrm{AUC}$ and half-life in both groups, indicating that intranasal dosing does not cause accelerated absorption $^{32}$.

\section{Efficacy}

LDX has been approved in the U.S., Canada, Australia, several European countries and Brazil; in Brazil it has been approved for the treatment of children, adolescents and adults.

The first Phase II, randomized, cross-over study, with controls (placebo and active control), compared LDX $(30,50$ or $70 \mathrm{mg}$ ) with placebo in 52 school-age children in a laboratory classroom setting ${ }^{23}$. Extended-release mixed amphetamine salts (10, 20 or $30 \mathrm{mg}$ ) were included as a reference arm during the study. Patients 6-12 years of age were initially treated with amphetamine salts for 3 weeks, followed by a double-blind crossover period during which they were given LDX, mixed amphetamine salts and placebo for 1 week each in a randomized order. Both active treatments were superior to placebo, using the Swanson, Kotkin, Agler, M-Flynn and Pelham Deportment Scale (SKAMP-DS) ${ }^{23}$. Significant improvements were also observed in the Clinical Global Impressions-Improvement (CGI-I) Scale, with $74 \%$ of patients receiving LDX classified as improved, $72 \%$ of those receiving mixed amphetamine salts and $18 \%$ of patients in the placebo group. In these evaluations, a greater percentage of children were considered to have been "very much improved" with LDX (32\%) compared with mixed amphetamine salts $(16 \%)^{23}$.

The second study was a Phase III, multi-center, placebocontrolled, forced-dose study in 290 children who received LDX 30,50 or $70 \mathrm{mg}^{33}$. Efficacy was observed after the first week of treatment, at which time the reductions in the ADHD Rating Scale IV (ADHD-RS-IV) scores were significantly greater for patients treated with LDX than among those receiving placebo. At the end of 4 weeks, significant reductions in the ADHD-RS-IV scale, CGI scale scores and Conners' Parents Rating Scale (CPRS) were found for each dose of LDX compared with placebo (all with $P<0.01$ ). The reductions in total ADHD-RS-IV scores were approximately 4 to 5 times greater with the active treatment than with placebo, with the greatest decreases observed for the $70 \mathrm{mg} \operatorname{LDX} \operatorname{dose}^{33}$.

Subsequent studies have investigated the use of LDX in longterm ADHD treatment. In a laboratory classroom study in 117 school-children, LDX provided therapeutic efficacy in as little as 1.5 hours after administration and the effects were maintained for up to 13 hours post-dose (last time point evaluated) ${ }^{29}$. Compared with placebo, significantly greater efficacy $(P<0.005)$ was found in the SKAMP and Permanent Product Measure of Performance scores with LDX at 1.5 and 13 hours post-dose ${ }^{29}$. The long-term efficacy of LDX was demonstrated in an 11-month open-label study involving 272 children ${ }^{34}$. Following dose-titration over the first 4 weeks, children 6-12 years of age were given 30,50 or $70 \mathrm{mg}$ doses of LDX per day for a maintenance period of 11 months. Efficacy (evaluated using the ADHD-RS and CGI scales) was pronounced, improved over the first 4 weeks, and was sustained throughout the study follow-up period. At the end of the study, there was a significant improvement in mean ADHD-RS scores $(P<0.0001)$, representing a change from baseline of more than $60 \%{ }^{34}$.

In a 4-week, double-blind study with forced titration involving 314 adolescents (13-17 years of age) with ADHD, LDX treatment resulted in significant reductions in ADHD symptoms ${ }^{35}$. At the end of the study, the mean change in the total ADHD-RS-IV scores was significantly greater than placebo for all doses $(30,50$ and $70 \mathrm{mg}$, $P \leq 0.0056)$. In addition, differences in total scores for all LDX doses were significant at all weeks of the study compared with placebo. At the end of the study, $69.1 \%$ of patients treated with LDX were rated as very much/much improved based on CGI-I scores compared with $39.5 \%$ of patients receiving placebo $(P<0.0001)^{35}$.

One of the key aspects of the treatment of ADHD is the need to control symptoms at different times during the day, something that could be problematic when using short-acting formulations. A recent study evaluating behavioral aspects using objective measures in the form of Conners' Parent Rating Scale-Revised (CPRS-R) in 336 children and adolescents throughout the day showed that there was a consistent benefit in the four subscales with a single, optimized dose of LDX $(30,50 \text { or } 70 \mathrm{mg})^{36}$.

Only one head-to-head study has directly compared LDX with another ADHD medication. This study was conducted in 267 children and adolescents, comparing LDX (in doses of $30,50 \mathrm{or} 70 \mathrm{mg}$ ) and atomoxetine $(0.5$ to $1.2 \mathrm{mg} / \mathrm{kg})$ over 9 weeks $^{37}$. LDX was associated with a significantly more rapid and robust treatment response than atomoxetine.

A recent phase III study in children and adolescents (6 to 17 years) with ADHD from 10 European countries included long-acting, osmotic-release oral system methylphenidate (OROS-MPH) as an active reference arm to provide validation of the study design ${ }^{38}$. Although not designed to support a formal statistical comparison of LDX and OROS-MPH, a post hoc analysis suggested a greater effect of LDX than OROS-MPH when assessed using the ADHDRS-IV (effect sizes 1.80 and 1.26, respectively) and CGI-I ${ }^{39}$. This finding appears to support a Cochrane review which demonstrated the efficacy of amphetamines in the treatment of ADHD in adults ${ }^{18}$, something demonstrated for LDX in recent studies in adults ${ }^{40}$.

Although there are no data on efficacy for the symptoms of depression and anxiety in children and adolescents with ADHD, a post hoc analysis ${ }^{41}$ of an open-label study over 7 weeks with LDX in children, evaluating the Behavior Rating Inventory of Executive Function (BRIEF) emotional control domain, revealed significant improvements associated with LDX treatment $(P<0.0001)$ in addition to improvements in the symptoms of ADHD.

Studies of pharmacological treatments for ADHD frequently use quality of life (QoL) and functional impairment indicators, aspects that are related but not necessarily proportional to the cardinal symptoms of ADHD. A 7-week, double-blind, placeboand active-controlled study of $\operatorname{LDX}^{42}$ utilised the Child Health and Illness Profile-Child Edition: Parent Report Form (CHIP-CE: PRF) and the Weiss Functional Impairment Rating Scale-Parent Report (WFIRS-P) questionnaires. This study found that both LDX and the active reference treatment, OROS-MPH, were associated with improvements in QoL and functioning, indicating treatment benefits beyond an improvement in the primary symptoms of ADHD.

\section{Safety}

Since LDX is a prodrug of $d$-amphetamine, one expects a tolerability profile similar to that of other amphetamines ${ }^{43}$; this aspect has been confirmed in the literature $\mathrm{e}^{23,32-35}$.

A systematic review and meta-analysis evaluating the drug options for ADHD management concluded that there were no significant differences in the relative risk of adverse events between non-stimulants and short-acting or extended-release stimulants ${ }^{44}$.

The tolerability and safety of LDX were investigated in a 4-week study including 290 children $^{33}$. The most common adverse events in children were loss of appetite, dizziness, dry mouth, irritability, insomnia, upper abdominal pain, nausea, vomiting and weight loss (Table 1). Most of the events were reported mainly in the first week, with a reduction over the 4 weeks of treatment tested, and the most frequent ones were loss of appetite (39\%vs. $4 \%$ for placebo) and insomnia $(19 \% \text { vs. } 3 \%)^{33}$. Although a study with small samples has suggested differences in the prevalence of adverse events that occur with the use of LDX when used in treatment-naïve patients in comparison with previously treated patients, the symptom profile was identical ${ }^{45}$. 
Table 1 . Summary of adverse events occurring in $>5 \%$ of children in any group after treatment with lisdexamfetamine dimesylate $(30,50$ or $70 \mathrm{mg})$ in short and long-term studies $\mathrm{s}^{33,44}$ - indicates no reported data

\begin{tabular}{|l|c|c|}
\hline \multirow{2}{*}{ Adverse event } & \multicolumn{2}{|c|}{ Occurrence (\%) } \\
\cline { 2 - 3 } & $\begin{array}{c}\text { Short-term } \\
\text { treatment } \\
(\mathrm{n}=218)^{33}\end{array}$ & $\begin{array}{c}\text { Long-term } \\
\text { treatment } \\
(\mathrm{n}=272)^{34}\end{array}$ \\
\hline Decreased appetite & 39.0 & 33 \\
\hline Insomnia & 18.8 & 17 \\
\hline Headache & 11.9 & 18 \\
\hline Upper abdominal pain & 11.9 & 11 \\
\hline Irritability & 9.6 & 10 \\
\hline Vomiting & 8.7 & 9 \\
\hline Nasopharyngitis & 5.0 & 10 \\
\hline Weight loss & 9.2 & 18 \\
\hline Nausea & 6.0 & - \\
\hline Dizziness & 5.0 & - \\
\hline Dry mouth & 4.6 & - \\
\hline Cough & 1.4 & 7 \\
\hline
\end{tabular}

\section{Long-term safety}

Results from a long-term treatment study showed that, after 11 months of treatment, adverse events occurring in more than $10 \%$ of patients included decreased appetite, headache, weight decrease, insomnia, upper abdominal pain and upper respiratory tract infection. Of all treatment-emergent adverse events, 97.5\% were considered to be of mild or moderate severity ${ }^{34}$. Long-term use of amphetamines has been associated with a temporary delay in growth rates in pediatric patients, something that appears to be significantly associated with weight loss. In a multicenter, open-label study with 272 children who received LDX $30-70 \mathrm{mg} /$ day for 12 months, patients showed a significant increase in height $(3.8 \mathrm{~cm})$, while there was no difference in weight (a non-significant mean gain of $272 \mathrm{~g}$ compared with baseline values) during the observation period ${ }^{34}$. When normalized for age and gender, compared with baseline, the mean change in percentile was -13.4 over 12 months (baseline percentile: $60.6 ; 12$ months percentile: 47.2$)^{34}$. Consistent with other psychostimulants, after treatment with LDX there was a slowing in growth rate measured by weight gain in comparison with children of the same age and gender ${ }^{34}$. The results from a non-controlled study of 281 children 6-13 years of age with ADHD receiving LDX for up to 15 months showed that LDX was associated with significant reductions in height and weight ${ }^{16}$. Compared with age-appropriate standards, children who were given LDX had reduced gains in height and weight ${ }^{16}$. The authors noted that more studies are required to determine the effect of LDX on final stature in adulthood and recommend that, as with other psychostimulants, weight and height should be monitored ${ }^{27,46}$, and treatment discontinuation should be considered in children who show inadequate growth and weight gain.

\section{Cardiovascular risk}

Based on data for amphetamines in general, cardiovascular risk associated with the use of LDX is believed to be low and changes in blood pressure (BP) and heart rate (HR) are considered to be small and not clinically significant $t^{47}$. In a Phase III study of 290 children, no significant change was observed in electrocardiogram (ECG) parameters or blood pressure ${ }^{33}$. However, LDX treatment was associated with significant increases in heart rate relative to placebo, with the largest increase (4-5 bpm) observed with the highest dose of LDX $(70 \mathrm{mg})^{33}$. An evaluation of cardiovascular parameters in 420 adult patients (18-55 years of age) with ADHD given doses of 30,50 and $70 \mathrm{mg} /$ day of LDX for 4 weeks showed no significant changes in ECG and blood pressure ${ }^{48}$. There was, however, a significant increase in heart rate and pulse for $\operatorname{LDX}(2.8,4.2$ and $5.2 \mathrm{bpm}$ for 30,50 and $70 \mathrm{mg}$ doses, respectively, compared with 0.0 for placebo), but the severity was considered to be mild to moderate and of minimal clinical concern ${ }^{48}$.

The use of amphetamines may be associated with changes in ECG parameters, although those changes have not been shown to be of clinical significance ${ }^{45}$. There was previous concern about cardiovascular risk associated with the use of methylphenidate and amphetamines in the treatment of ADHD in children ${ }^{49}$, but evidence indicates that cardiovascular events are rare (and frequently associated with a pre-existing pathology) and there is no increase in the risk of sudden death ${ }^{45,47}$. The frequency of sudden death with the use of stimulants has been estimated to be around 0.56 deaths per 1 million prescriptions ${ }^{50}$, which is considered to be lower than that of the general public ${ }^{45}$. Despite there being no reports of cases of sudden death associated with the use of LDX in the literature, the probability of sudden death occurring must be considered to be similar to that of other psychostimulant medications ${ }^{51}$.

\section{Potential for abuse}

Psychostimulants as a group have a potential for abuse which must be taken into consideration by the physician. There have been reports of non-medical use by healthy individuals to increase cognitive performance and, in particular, academic performance ${ }^{52-54}$. One possible advantage of LDX is the absence of clinically significant psychoactive effects when administered by intranasal or intravenous means, in addition to the absence of an accelerated effect (in terms of $\mathrm{C}_{\max }$ or $\mathrm{T}_{\max }$ ) when used by intranasal means $\mathrm{s}^{32}$, potentially reducing the probability of abuse and misuse ${ }^{55}$. In addition, since LDX is an inactive prodrug, it is believed that the slow release of $d$-amphetamine (produced by hydrolysis of LDX) produces a slow, steady therapeutic effect, potentially avoiding the large/fast increases in dopamine that are associated with the reinforcing effects of drug abuse $\mathrm{e}^{56}$.

The abuse potential of LDX is considered to be less than that of $d$-amphetamine. In a study of potential abuse comparing both treatments in adult stimulant abusers, LDX $50 \mathrm{mg}$ administered intravenously did not result in significant abuse-related craving scores $(P=0.290)$ when compared with placebo ${ }^{19}$. The results indicated that after $50 \mathrm{mg}$ doses of LDX and $20 \mathrm{mg}$ doses of $d$-amphetamine administered intravenously, only $d$-amphetamine differed significantly from the placebo in drug-craving ratings ${ }^{19}$. In a placebo-controlled study, orally-administered LDX (50, 100 and $150 \mathrm{mg}$ ) was compared with $d$-amphetamine $40 \mathrm{mg}$ (equivalent to $100 \mathrm{mg}$ of LDX) in adults (18-55 years of age) with a history of stimulant abuse $\mathrm{e}^{22}$. Of the doses tested, only $d$-amphetamine and LDX at the highest dose $(150 \mathrm{mg})$ differed significantly from placebo in craving scores on the Drug Rating Questionnaire-Subject (DRQS) scale. In a pair-wise comparison of equivalent doses, $d$-amphetamine (40 mg) was associated with significantly higher craving scores compared with LDX (50 or $100 \mathrm{mg}$ ), indicating that abuse liability ("drug craving") is attenuated with $\mathrm{LDX}^{22}$. There are no studies available on the abuse potential of LDX compared with other controlled-release stimulants used in the treatment of ADHD, and there are as yet no data available for populations other than adults.

\section{Discussion}

LDX is an inactive prodrug that is metabolized to the active fraction ( $d$-amphetamine) through rate-limited hydrolysis, resulting in the steady release of $d$-amphetamine and a prolonged effect following a single daily dose. In controlled clinical studies, LDX proved to be effective for the treatment of ADHD in children and adolescents, with results comparable to those of other available psychostimulants. The therapeutic effects of LDX are achieved 
less than 1.5 hours after administration and are maintained for up to 13 hours. In addition, LDX is effective in long-term maintenance therapy. The safety and tolerability profile of LDX is similar to that observed with other psychostimulants. The pharmacokinetic profile of LDX is associated with a lower abuse potential than immediaterelease psychostimulants.

\section{Conflicts of interest}

Dr. Paulo Mattos is a consultant and lecturer for the Janssen-Cilag, Novartis and Shire companies, and coordinates a clinical research group that receives funding from the Novartis and Shire companies. This study had the support of the pharmaceutical company (Shire) that markets the drug, sponsoring preliminary literature search, translation and draft preparation by specialized companies (in Science Communications and Oxford PharmaGenesis $\left.{ }^{\mathrm{TM}} \mathrm{Ltd}\right)$. The author did not receive any fee related to this manuscript.

\section{References}

1. Wolraich M, Brown L, Brown RT, DuPaul G, Earls M, Feldman HM, et al. ADHD: clinical practice guideline for the diagnosis, evaluation, and treatment of attention-deficit/hyperactivity disorder in children and adolescents. Pediatrics. 2011;128:1007-22.

2. Greene RW, Biederman J, Faraone SV, Monuteaux MC, Mick E, DuPre EP, et al. Social impairment in girls with ADHD: patterns, gender comparisons, and correlates. J Am Acad Child Adolesc Psychiatry. 2001;40:704-10.

3. DeShazo Barry T, Lyman RD, Grofer Klinger L. Academic underachievement and attention-deficit/hyperactivity disorder: the negative impact of symptom severity on school performance. J School Psychol. 2002;40:259-83.

4. Harpin VA. The effect of ADHD on the life of an individual, their family, and community from preschool to adult life. Arch Dis Child. 2005;90(Suppl 1):i2-7.

5. Fletcher J, Wolfe B. Long-term consequences of childhood ADHD on criminal activities. J Ment Health Policy Econ. 2009;12:119-38.

6. Pastura GM, Mattos P, Araujo AP. Academic performance in ADHD when controlled for comorbid learning disorders, family income, and parental education in Brazil. J Atten Disord. 2009;12:469-73.

7. Polanczyk G, de Lima MS, Horta BL, Biederman J, Rohde LA. The worldwide prevalence of ADHD: a systematic review and metaregression analysis. Am J Psychiatry. 2007;164:942-8.

8. Rohde LA, Biederman J, Busnello EA, Zimmermann H, Schmitz M, Martins S, et al. ADHD in a school sample of Brazilian adolescents: a study of prevalence, comorbid conditions, and impairments. J Am Acad Child Adolesc Psychiatry. 1999;38:716-22.

9. Polanczyk G, Laranjeira R, Zaleski M, Pinsky I, Caetano R, Rohde LA. ADHD in a representative sample of the Brazilian population: estimated prevalence and comparative adequacy of criteria between adolescents and adults according to the item response theory. Int J Methods Psychiatr Res. 2010;19:177-84.

10. Anselmi L, Menezes AM, Barros FC, Hallal PC, Araujo CL, Domingues $\mathrm{MR}$, et al. Early determinants of attention and hyperactivity problems in adolescents: the 11-year follow-up of the 1993 Pelotas (Brazil) birth cohort study. Cad Saude Publica. 2010;26:1954-62.

11. Pastura G, Mattos P, Araujo AP. [Prevalence of attention deficit hyperactivity disorder and its comorbidities in a sample of school-aged children]. Arq Neuropsiquiatr. 2007;65:1078-83.

12. Goodman DW. The consequences of attention-deficit/hyperactivity disorder in adults. J Psychiatr Pract. 2007;13:318-27.

13. Gomes M, Palmini A, Barbirato F, Rohde LA, Mattos P. Knowledge about attention-deficit hyperactivity disorder in Brazil. J Bras Psiquiatr. 2007;56:94-1001.

14. Pelham WE Jr, Fabiano GA. Evidence-based psychosocial treatments for attention-deficit/hyperactivity disorder. J Clin Child Adolesc Psychol. 2008;37:184-214.

15. Oliveira IR, Sena EP. Manual de psicofarmacologia clínica. $2^{\mathrm{a}}$ ed. Rio de Janeiro: Guanabara Koogan; 2006.
16. Faraone SV, Spencer TJ, Kollins SH, Glatt SJ. Effects of lisdexamfetamine dimesylate treatment for ADHD on growth. J Am Acad Child Adolesc Psychiatry. 2010;49:24-32.

17. Krishnan SM, Pennick M, Stark JG. Metabolism, distribution and elimination of lisdexamfetamine dimesylate: open-label, single-centre, phase I study in healthy adult volunteers. Clin Drug Investig. 2008;28:745-55.

18. Castells X, Ramos-Quiroga JA, Bosch R, Nogueira M, Casas M. Amphetamines for attention deficit hyperactivity disorder (ADHD) in adults. Cochrane Database Syst Rev. 2011;(6):CD007813.

19. Jasinski DR, Krishnan S. Human pharmacology of intravenous lisdexamfetamine dimesylate: abuse liability in adult stimulant abusers. J Psychopharmacol. 2009;23:410-8.

20. Najib J. The efficacy and safety profile of lisdexamfetamine dimesylate, a prodrug of d-amphetamine, for the treatment of attention-deficit/ hyperactivity disorder in children and adults. Clin Ther. 2009;31:142-76.

21. Boellner SW, Stark JG, Krishnan S, Zhang Y. Pharmacokinetics of lisdexamfetamine dimesylate and its active metabolite, d-amphetamine, with increasing oral doses of lisdexamfetamine dimesylate in children with attention-deficit/hyperactivity disorder: a single-dose, randomized, open-label, crossover study. Clin Ther. 2010;32:252-64.

22. Jasinski DR, Krishnan S. Abuse liability and safety of oral lisdexamfetamine dimesylate in individuals with a history of stimulant abuse. J Psychopharmacol. 2009;23:419-27.

23. Biederman J, Boellner SW, Childress A, Lopez FA, Krishnan S, Zhang Y Lisdexamfetamine dimesylate and mixed amphetamine salts extendedrelease in children with ADHD: a double-blind, placebo-controlled, crossover analog classroom study. Biol Psychiatry. 2007;62:970-6.

24. Ermer J, Homolka R, Martin P, Buckwalter M, Purkayastha J, Roesch B. Lisdexamfetamine dimesylate: linear dose-proportionality, low intersubject and intrasubject variability, and safety in an open-label single-dose pharmacokinetic study in healthy adult volunteers. J Clin Pharmacol. 2010;50:1001-10.

25. Ermer JC, Adeyi BA, Pucci ML. Pharmacokinetic variability of longacting stimulants in the treatment of children and adults with attentiondeficit hyperactivity disorder. CNS Drugs. 2010;24:1009-25.

26. Auiler JF, Liu K, Lynch JM, Gelotte CK. Effect of food on early drug exposure from extended-release stimulants: results from the Concerta, Adderall XR Food Evaluation (CAFE) Study. Curr Med Res Opin. 2002;18:311-6.

27. Adderall XR. US prescribing information. Wayne, PA: Shire US, Inc.; 2010.

28. Krishnan S, Zhang Y. Relative bioavailability of lisdexamfetamine 70$\mathrm{mg}$ capsules in fasted and fed healthy adult volunteers and in solution: a single-dose, crossover pharmacokinetic study. J Clin Pharmacol. 2008;48:293-302.

29. Wigal SB, Kollins SH, Childress AC, Squires L. A 13-hour laboratory school study of lisdexamfetamine dimesylate in school-aged children with attention-deficit/hyperactivity disorder. Child Adolesc Psychiatry Ment Health. 2009;3:17.

30. Lopez F, Childress A, Adeyi BA, Dirks B, Babcock T, Schekner B, et al., editors. Sustained effects of lisdexamfetamine dimesylate across the day in children aged 6 to 12 years with ADHD: Symptom Control and Rebound American Academy of Child and Adolescent Psychiatry. New York, NY; 2010.

31. Sevak RJ, Stoops WW, Rush CR. Behavioral effects of d-amphetamine in humans: influence of subclinical levels of inattention and hyperactivity. Am J Drug Alcohol Abuse. 2010;36:220-7.

32. Ermer J, Dennis K, Haffey MB, Doll WJ, Sandefer EP, Buckwalter M, et al. Intranasal versus oral administration of lisdexamfetamine dimesylate: a randomized, open-label, two-period, crossover, single-dose, single-centre pharmacokinetic study in healthy adult men. Clin Drug Investig. 2011;31(6):357-70.

33. Biederman J, Krishnan S, Zhang Y, McGough JJ, Findling RL. Efficacy and tolerability of lisdexamfetamine dimesylate (NRP-104) in children with attention-deficit/hyperactivity disorder: a phase III, multicenter, randomized, double-blind, forced-dose, parallel-group study. Clin Ther 2007;29:450-63.

34. Findling RL, Childress AC, Krishnan S, McGough JJ. Long-term effectiveness and safety of lisdexamfetamine dimesylate in school-aged children with attention-deficit/hyperactivity disorder. CNS Spectr. 2008;13:614-20. 
35. Findling RL, Childress AC, Cutler AJ, Gasior M, Hamdani M, FerreiraCornwell MC, et al. Efficacy and safety of lisdexamfetamine dimesylate in adolescents with attention-deficit/hyperactivity disorder. J Am Acad Child Adolesc Psychiatry. 2011;50:395-405.

36. Coghill DR, Banaschewski T, Lecendreux M, Zuddas A, Dittmann RW, Otero IH, et al. Efficacy of lisdexamfetamine dimesylate throughout the day in children and adolescents with attention-deficit/hyperactivity disorder: results from a randomized, controlled trial. Eur Child Adolesc Psychiatry. 2014;23(2):61-8.

37. Dittmann R, Cardo E, Nagy P, Anderson CS, Bloomfield R, Caballero $\mathrm{B}$, et al. Efficacy and safety of lisdexamfetamine dimesylate and atomoxetine in the treatment of attention-deficit/hyperactivity disorder: a head-to-head, randomized, double-blind, phase IIIb study. CNS Drugs. 2013;27(12):1081-92.

38. Coghill D, Banaschewski T, Lecendreux M, Soutullo C, Johnson M, Zuddas A, et al. European, randomized, phase 3 study of lisdexamfetamine dimesylate in children and adolescents with attention-deficit/hyperactivity disorder. Eur Neuropsychopharmacol. 2013;23(10):1208-18.

39. Soutullo C, Banaschewski T, Lecendreux M, Johnson M, Zuddas A, Anderson C, et al. A post hoc comparison of the effects of lisdexamfetamine dimesylate and osmotic-release oral system methylphenidate on symptoms of attention-deficit hyperactivity disorder in children and adolescents. CNS Drugs. 2013;27(9):743-51.

40. Adler LA, Lynch LR, Shaw DM, Wallace SP, O'Donnell KE, Ciranni MA, et al. Effectiveness and duration of effect of open-label lisdexamfetamine dimesylate in adults with ADHD. J Atten Disord. 2013 May 8. [Epub ahead of print]

41. Katic A, Dirks B, Babcock T, Scheckner B, Adeyi B, Richards C, et al. Treatment outcomes with lisdexamfetamine dimesylate in children who have attention-deficit/hyperactivity disorder with emotional control impairments. J Child Adolesc Psychopharmacol. 2013;23(6):386-93.

42. Banaschewski T, Soutullo C, Lecendreux M, Johnson M, Zuddas A, Hodgkins $\mathrm{P}$, et al. Health-related quality of life and functional outcomes from a randomized, controlled study of lisdexamfetamine dimesylate in children and adolescents with attention deficit hyperactivity disorder. CNS Drugs. 2013;27(10):829-40.

43. Popovic B, Bhattacharya P, Sivaswamy L. Lisdexamfetamine: a prodrug for the treatment of attention-deficit/hyperactivity disorder. Am J Health Syst Pharm. 2009;66:2005-12.

44. Peterson K, McDonagh MS, Fu R. Comparative benefits and harms of competing medications for adults with attention-deficit hyperactivity disorder: a systematic review and indirect comparison meta-analysis. Psychopharmacology (Berl). 2008;197:1-11.

45. Wigal SB, Wong AA, Jun A, Stehli A, Steinberg-Epstein R, Lerner MA. Adverse events in medication treatment-naïve children with attention-deficit/hyperactivity disorder: results from a small, controlled trial of lisdexamfetamine dimesylate. J Child Adolesc Psychopharmacol. 2012;22(2):149-56.

46. Focalin XR (dexmethylphenidate hydrochloride extended release capsules): US prescribing information. East Hanover, NJ: Novartis Pharmaceuticals Corporation; 2012.

47. Stiefel G, Besag FM. Cardiovascular effects of methylphenidate, amphetamines and atomoxetine in the treatment of attention-deficit hyperactivity disorder. Drug Saf. 2010;33:821-42.

48. Adler LA, Weisler RH, Goodman DW, Hamdani M, Niebler GE. Short-term effects of lisdexamfetamine dimesylate on cardiovascular parameters in a 4-week clinical trial in adults with attention-deficit/ hyperactivity disorder. J Clin Psychiatry. 2009;70:1652-61.

49. Wilens TE, Prince JB, Spencer TJ, Biederman J. Stimulants and sudden death: what is a physician to do? Pediatrics. 2006;118:1215-9.

50. Knight M. Stimulant-drug therapy for attention-deficit disorder (with or without hyperactivity) and sudden cardiac death. Pediatrics. 2007;119:154-5.

51. Cowles BJ. Lisdexamfetamine for treatment of attention-deficit/hyperactivity disorder. Ann Pharmacother. 2009;43:669-76. 